\title{
The feminization of dentistry and the perceptions of public service users about gender issues in oral health
}

\author{
A feminização da odontologia e as percepções dos usuários do \\ serviço público sobre as questões de gênero em saúde bucal
}

Maria da Graça Kfouri (https://orcid.org/0000-0002-9615-3508) ${ }^{1}$

Simone Tetu Moysés (https://orcid.org/0000-0003-4861-9980) ${ }^{2}$

Marilisa Carneiro Leão Gabardo (https://orcid.org/0000-0001-6832-8158) ${ }^{3}$

Antonio Carlos Nascimento (https://orcid.org/0000-0002-3804-9905) ${ }^{3}$

Saulo Vinicius da Rosa (https://orcid.org/0000-0002-7107-9575) ${ }^{2}$

Samuel Jorge Moysés (https://orcid.org/0000-0003-3075-6397) ${ }^{2}$

${ }^{1}$ Departamento de Saúde Coletiva, Universidade Federal do Paraná Litoral. R. Jaguariaíva 512, Caiobá. 83260-000 Matinhos PR Brasil.mkfouri@ufpr.br ${ }^{2}$ Escola de Ciências da Vida, Pontifícia Universidade Católica do Paraná. Curitiba PR Brasil.

${ }^{3}$ Escola de Saúde e Biociências, Universidade Positivo. Curitiba PR Brasil.

\begin{abstract}
It was investigated the perception of service users in relation to the professional practice of dentists, based on gender differences. The Primary Care Assessment Tool (PCATool) was applied to 900 users of the Public Service in Curitiba, PR, Brazil. Sixty clinics were selected using random sampling, divided between conventional Primary Health Care (PHC) Units and PHC with Family Health System Units. The attributes of PHC that compound the PCATool were analyzed. A question was added about user preference regarding the gender of the dental professional, thus generating four dyads derived from user gender/dentist gender ( $F F, F M, M M, M F)$. The attributes were linked to the dyads by applying the independent sample $t$ test. Using logistic regression, the dyads were linked to 23 factors relating to scaled-up care in PHC. Many users showed a clear preference for being attended by female dentists. Users who prefer to be cared for by women tend to better evaluate PHC on issues related to "active listening", while those who prefer to be cared for by male dentists highlight the attributes of "care integration" and "community guidance". In other factors and attributes studied, there is no difference between the care given by men or women, regardless the unit.
\end{abstract} Key words Dentist, Gender, Primary health care.
Resumo Investigou-se a percepção dos usuários do serviço quanto à prática profissional dos dentistas, com base em diferenças de gênero. O Primary Care Assessment Tool (PCATool) foi aplicado a 900 usuários do Serviço Público de Curitiba, $P R, B r a s i l$ Sessenta clínicas odontológicas foram selecionadas usando amostragem aleatória, divididas entre unidades de Atenção Primária à Saúde (APS) convencional e unidades de APS com Estratégia Saúde da Família. Os atributos da APS no PCATool foram analisados. Uma questão foi adicionada acerca da preferência do usuário em relação ao gênero do dentista, gerando quatro díades derivadas da combinação do gênero do usuário/gênero do dentista (FF, FM, MM, MF). Os atributos foram ligados às díades pelo teste t para amostras independentes. Por regressão logística, as díades foram relacionadas a 23 fatores referentes aos cuidados ampliados na APS. Muitos usuários mostraram preferencia por dentistas mulheres. Esses tendem a avaliar melhor os cuidados de saúde primários quanto à "escuta ativa e qualificada", enquanto aqueles que preferem ser atendidos por homens destacam os atributos de "integração do cuidado" e "orientação comunitária". Em outros fatores e atributos estudados, não há diferença entre o atendimento prestado por homens ou mulheres, independentemente da unidade.

Palavras-chave Dentista, Gênero, Atenção primária à saúde. 


\section{Introduction}

The increase in the number of women working in health professions is a phenomenon that occurs in several countries ${ }^{1,2}$. Women progressively engaged in occupational positions that were considered mostly designed to male dominance a few decades $\mathrm{ago}^{3}$, as is the case of Dentistry ${ }^{4,5}$. The reasons for this change are many, for example, the insertion of women in the labor market is strongly accentuated from the 1960s onwards, with the struggle of feminist movements and later on as a profession achievement.

The Brazilian professional register office of 2017 reveals that there are 296,839 dentists registered in the Federal Council of Dentistry. Unlike the USA and most European countries, women are currently absolute majority in Brazilian Dentistry, corresponding to almost $60 \%$ of the number of registered professionals in the whole country ${ }^{6}$. Meanwhile, it is projected that by the year $2020,20 \%$ of all dental practitioners in the United States will be women ${ }^{7}$. The female majority has shown to be a reality in other countries like Holland $^{8}$ and South Africa ${ }^{9}$, confirming a trend of feminization in Dentistry in several contexts. In Brazil the number of new female students and graduating is expressive according to the most recent Sinopse Estatística da Educação Superior 2016 - Synopsis of Higher Education of $2016^{10}$.

In Brazil, since 2003, there was a change in the State's response to the oral health policy. The National Oral Health Policy, which is called "Smiling Brazil", was issued in 2004 and is still in force; has become one of the main vectors for the public employability of dentists. It is estimated that a proportion of dentists in the National Health Service (the Sistema Único de Saúde SUS) progresses from $27-30 \%$ during the period 2003-2014, of the total number of registered professionals ${ }^{11}$. Women are the bulk with regard to Brazilian dental surgeons working in public services, particularly in the Primary Health Care (PHC); they are also the majority in the Family Health Strategy (FHS), with a percentage of $58 \%$ while men are $42 \%$. Family health teams, which requires in many localities a full-time working day $^{12}$, are geographically structured, primarily in areas of greater social vulnerability, covering populations of up to 1,000 families each. Each FHS team member has roles and responsibilities, according to their competencies to work on the interdisciplinary team, and national guidelines help to adjust FHS responses locally to community health problems. In this aspect, the Brazilian situation coincides with the United Kingdom, with women dentists adhering more to direct care with the community, although also occupying managerial positions and interested in working privately ${ }^{13,14}$.

From the 1970s onward, the notion of work as a measurable social activity, which can be taken as a sociological problem, advanced in the critical perspective over the framework in which the "masculine" gender is presented as a universal, "naturalized" category. Gender relations were little contemplated, only limited to considerations about the productivity of men and women. In trying to better understand the meanings of the working world, including the subjective standpoint, new studies make a point with the "social relations of gender", which problematize the "natural" sexual division of labor, and extend the notion of work itself to the sphere of cultural production $^{15}$.

Of particular interest for this article, there are reports in the literature about the opinion of service users as to the professional care provided by dental surgeons in the public sector ${ }^{16,17}$. In general, they show patients valuing communication and humanization in the care they receive. The preference by women dentists was identified by some authors, related to care, patience, and relaxed filling ${ }^{17,18}$. Outstanding, these results were found in the international literature, which leads to the multicultural issues involved. One of the works is from India, where the role of the woman assumes, until today, a configuration dependent on the male figure. In view of this scenario, it is important to investigate such perceptions in Brazilian public dental services users, regarding the fact of whether or not they make any quality of care distinction as to the gender of the professional who cares of them. Nevertheless, it is necessary to record that in the public health services in Brazil there is generally no option of choosing the professional on the part of the user of the service.

Evaluation of PHC reflects the extent to which the structure of the service and the professionals who provides it demonstrates a welcoming approach, humanization and technical competence in solving low complexity health problems ${ }^{19}$. It is in PHC, the entry point to the network of health service, that the user is able to perceive the effectiveness of concrete health care and promotion actions, and to express perceptions of some gender differences in this context ${ }^{19}$.

The main objective of this study was to identify whether service users manifest preference for 
This article integrates a broader cross-sectional, quantitative and qualitative study, and focuses on partial data of the quantitative approach. The socio-geographic context is the city of Curitiba and its own municipal network of 136 Health Facilities, among which there were, in 2013, 53 PHC Units and 55 PHC Units that incorporate the FHS. From the 108 Units that serve the population of interest for the present research, 102 include dental clinics at the time of the field research, in which the oral health teams - dental surgeons, oral health technicians and auxiliaries - undertake oral health promotion, prevention and restoration. They also develop collective actions, which comprise tackling inequalities and programmatic inclusion of vulnerable population, health education fostering autonomy for oral health self-efficacy, and community empowerment that take place primarily in community social facilities ${ }^{20}$.

Sixty dental clinics $(58.8 \%$ of the total) were selected using random sampling, divided between 30 conventional PHC Units and 30 PHC/FHS Units. In these 60 Units, male and female dentists work in the proportion of 1 to 3, i.e. 53 men and 150 women. The selection of users came from records of the Primary Care Information System (PCIS) of the Municipal Health Department - a computerized system that registers all families that use the health services. Using the PCIS, 900 households were selected. The respondents had to be 18 years old or over and not have any physical or mental disability capable of compromising the interview, in addition to being registered with the sampled Unit for at least two years, since in this way they would provide reliable information as regular users of those services.

After signing a Term of Free and Informed Consent, users of both genders were interviewed, forming blocks of 15 individuals for each of the 60 Units in the sample. The users' response rate was $100 \%(n=900)$, owing to the strategy adopted of scheduling and return visits as convenient for the respondents. These procedures were approved by the Pontifícia Universidade Católica do Paraná Research Ethics Committee dated April $5^{\text {th }} 2011$.

In order to investigate the preferences of the users of public health system in Curitiba, regarding the gender of the dental professionals, the Primary Care Assessment Tool (PCATool ${ }^{21}$ was used for data collection, adapted for oral health through its "Users" version, validated from English into Portuguese ${ }^{22}$. In addition to the desirable attributes derived from Primary Health Care (PHA), PCATool also investigates the "Degree of Affiliation" of users to the health service ${ }^{19-23}$. This criterion denotes the recognition a user has for a health professional or health service which the user considers to be a reference whenever they need it ${ }^{14}$.

"PCATool-Users" comprises 93 questions, which are divided into groups to form 10 attributes that qualify the PHC. The attributes denominated "Primary Attributes" include: 1) First contact access, 2) First contact, 3) Continuity of care, 4) Information system, 5) Care integration, 6) Clinical comprehensiveness and 7) Extended comprehensiveness; and the "Derived Attributes" include: 8) Family Orientation, 9) Cultural Competence and 10) Community Orientation.

In order to collect data regarding user preference as to the gender of the dental professional, the following question was included in the PCATool-Users questionnaire: "If you could choose, do you prefer to be cared for by a dentist of the same gender as yours?" The reply options were "yes", "no" and "indifferent". The question was classified using the code K10 on the original instrument.

The presence of the question about the professional's gender on the instrument provides support to this analytical study. Methodologically, it is important to emphasize that gender is a social construct and the dissemination of the use of this analytical category has shown that it is not univocal. Gender deals with social relationships in which women and men are mutually involved. This dissemination has also revealed the complexity of using the category, since gender interacts with complex dimensions of the human being, as well as with daily practices, such as the work. The literature indicates that the gender category has been classified into three main types ${ }^{24}$ :

1) A descriptive approach of the sex of the studied subjects, point out their features.

2) Gender as a theoretical assumption, thus the analysis of differences between men and women that is not based on empirical data.

3) A concept that is derived from the empirical material, as an interpretive device for the 
"constructions" in the concrete situation, rather than as "truths" of the subjects; so, taking this conceptual construction as an analytical category, and not a descriptive category.

For the remaining questions respondents had to opt from one of five possible answers organized on a Likert Scale: "Certainly, yes" (score =4); "Probably, yes" (score = 3); "Probably not" $($ score $=2)$; "Certainly not" ( score $=1$ ); and "I don't know or can't remember" (score $=0$ ). Scores between 0 (zero) and 100 (one hundred) were initially obtained for each of the attributes.

The scores of the PHC attributes were calculated by taking the total of the scores of the factors, divided by the total number of factors for each attribute, to provide that final mean score of the attribute. All of the scores, for each of the attributes, were later transformed on a scale ranging from 0 (zero) to 10 (ten) points, so that the PHC "Primary Score" and the "Overall Score" could be calculated. The "Primary Score" was measured by taking the sum of the mean scores of the seven "Primary Attributes", plus the score given to the "Degree of Affiliation" and dividing by the number of components. The "Overall Score" was calculated using the same principle, although in this case the mean scores of the three PHC "Derived Attributes" were included.

For the gender question, the data were grouped together in dyads based on the gender of the respondent and their choice as to the gender of the dental professional. There are therefore four resulting dyads:

1 - male patient / preference for male dentist $(\mathrm{MM})$

2 - male patient / preference for female dentist (MF)

3 - female patient / preference for male dentist (FM)

4 - female patient / preference for female dentist (FF)

These data were tabulated using Excel (Microsoft Corporation) spreadsheets and later transferred to the Statistica 7.0 program (Starsoft, Inc. Tulsa, USA). The analyses were divided into the following stages:

a) Evaluation of the dyad frequencies: The dyad frequencies were compared using the Chi square goodness of fit test. The following combinations were compared: 1) MM, MF, FM and FF; 2) Same gender dyads versus Different gender dyads; 3) Female gender dentist dyads versus Male gender dentist dyads.

b) Comparison of the PHC attributes (primary and derived) and scores (overall and pri- mary) among the groups of users who preferred to be cared for by dentists of the male or female gender. The analysis of the user groups, both for attributes and for scores, was applied using the independent sample $t$ test, testing the null hypothesis that the mean of the two groups was equivalent.

c) Development of the model of factors that are related to the user's choice of the dentist's gender. This stage was undertaken by applying logistic regression analysis, based on 23 questions (A2, A3, D1-14, H1-5, H9, I3, I6) contained in the PCTool-Users instrument, the contents of which are related to characteristics regarding personalized care (an attribute of extended care), recognition of the user as an individual being and humanized care, active listening as well as certain factors that comprise care extended to the user's family.

All the questions were analyzed in relation to the categorical answers, organized into three possibilities: considering "Yes" for the alternatives "Certainly, yes" and "Probably, yes" and considering "No" for the alternatives "Certainly not" and "Probably not"; finally, the "I don't know, I can't remember" answers were considered as a third category.

The stepwise forward method of the logit model was used for the logistic regression analysis, using the binary answer type. This involved the following stages:

a) Selecting the variables using the criterion of $p<0.20$ of the odds ratio being statistically equivalent to 1.00 ;

b) Obtaining a model with a reduced number of variables, selected by applying the criterion of $\mathrm{p}<0.10$ of the adjusted odds ratio being statistically equivalent to 1.00 . The logistic analysis regression included these variables, even if they did not present $\mathrm{p}<0.05$ because they generated the most parsimonious model, i.e. they presented the lowest Akaike Information Criterion (AIC). If the variables with $p>0.05$ were removed, the model would be less parsimonious and would therefore have less explanatory power;

c) Obtaining a final model after testing for all possible multiple interactions, using the Newton-Raphson algorithm for likelihood function optimization.

The analysis was finalized by calculating the odds ratio, estimating the probability of the occurrence of the event of one of the gender dyads analyzed for each type of Health Unit, given the combination of the variables exposed in the predictive model. 


\section{Results}

\section{Evaluation of dyad frequency}

It was found that there were significant statistical differences when comparing the frequencies of all the user/dentist dyads (MM - 14.0\%, $\mathrm{MF}-27,0 \%, \mathrm{FF}-47,0 \%, \mathrm{FM}-12,0 \%)(\mathrm{p}<0.01)$, whereby the FF dyad is significantly greater compared to the rest. When comparing same gender dyads significant difference was also observed $(\mathrm{p}<0.01)$, whereby same gender dyads $(61,0 \%)$ have greater frequency when compared to different gender dyads $(39,0 \%)$.

When comparing the dyads that have the female or male gender of dentists as their preference or choice, significant difference was also observed $(\mathrm{p}<0.01)$, whereby the dyads with preference for the female gender have greater frequency $(75.0 \%)$ when compared to those of the male gender $(25.0 \%)$.

It should be emphasized that the dyad frequencies appear to coincide with the care routine effectively provided in the Units. When analyzing the list of the professionals allocated in the respective Unit of the subjects studied, $98.5 \%$ of the stated preferences coincide with the gender of the professional who does in fact care on an everyday basis for each respondent of the sample used in this study.

\section{Comparison of the attributes and scores between the groups of users who prefer to be cared for by dentists of the male or female gender}

When comparing the scores of the PCATool between service users who prefer to be cared for by male or female gender, it was found that the attributes "First contact access", "First contact", "Continuity of care", "Information system", "Clinical integrality", "Extended integrality", "Family guidance" and "Cultural competence" do not present significant statistical differences between the groups ( $p>0.05)$ (Table 1). However, the attributes "Care integration" and "Community guidance" presented significant statistical differences $(p<0.05)$. In both cases, the means were significantly greater when the preferred gender of the dentist was male (Table 1).

There was no statistical difference between the groups when comparing the 'Primary Score' ( $p>0.05)$. However, when comparing the 'Overall Score' it was found that the group that prefers dentists of the male gender obtained a higher mean than the group that prefers dentists of the female gender $(\mathrm{p}<0.05)$ (Table 1$)$.

\section{Development of the model of factors that relate to the user's choice of the gender of dentists}

In this phase of the analysis, logistic regression was performed to the combination of the answers given to the 23 PCATool-Users selected questions, including all the variables. Some factors demonstrated statistical significance between the answers relating to the variables: "nature of the Health Units" (Conventional PHC or Family Health Strategy) and MM, MF, FF and FM dyads. A summary of these combinations is explained in Table 2, along with the wording of the four questions (D2, D5, D7 and D11) that presented a significant $p$ value. It can be seen that there is not an evident pattern in the answers to the questions that presented statistical significance, whether in relation to the dyads or in relation to the nature of the Units. With regard to the dyads, a discrete preponderance of "yes" answers can be seen for service users who prefer to be cared for by women dentists, in the questions relating to active listening and understanding of the problems. This can be considered to be a trend, although results with $\mathrm{p}>0.05$ and confidence intervals that include the value of 1 , can only be considered as trends that do not allow categorical generalizations.

According to the model chosen, adequate adjustment of the multivariate model can be seen (Table 3), for the dyads of male PHC/FHS Units users with a predictive power of $91.2 \%$. In the case of the female FHS user dyads, it was possible to get a significant adjustment $(\mathrm{p}=0.03)$, although with predictive power of just $28.1 \%$. Despite the low explanatory power, it was possible to observe that female service users who prefer dentists of the same gender (FF) state that the dentist usually knows them more as a patient than as a person (question D7), and this fact is 2.95 greater than the FM dyad (OR=2.95; 95\%CI 1.09-7.93). Here, the result suggests that the women users think that women dentists show themselves to be more interested in the strictly professional relationship, in detriment to the human side.

With regard to the FF dyad (FHS Unit), the odds of replying negatively to question D5 (does the HU dentist allow enough time for you to talk about your concerns?) were not significant $(\mathrm{p}=0.22$ in Table 3$)$. However, in the opposite relationship, the FM dyad is two times more likely to answer "No" to the same question, although 
Table 1. Statistics resulting from the comparison of the attributes and scores between the groups that prefer to be cared for by dentists of the male or female gender. Curitiba, 2013.

\begin{tabular}{lccccccc}
\hline \begin{tabular}{c} 
Professional's gender according \\
to user preference X PHC \\
\multicolumn{1}{c}{ Attributes and Scores }
\end{tabular} & \multicolumn{2}{c}{$\mathbf{n}$} & \multicolumn{7}{c}{ Mean \pm SD } & $\mathbf{t}^{*}$ & GL $^{* *}$ & P \\
\cline { 2 - 8 } & Man & Woman & Man & Woman \\
\hline First contact & 190 & 557 & $6.89 \pm 1.50$ & $6.94 \pm 1.66$ & -0.32 & 745 & 0.75 \\
Accessibility & 190 & 557 & $5.85 \pm 0.84$ & $5.84 \pm 0.75$ & 0.14 & 745 & 0.89 \\
Continuity of care & 190 & 557 & $7.29 \pm 0.70$ & $7.30 \pm 0.70$ & -0.02 & 745 & 0.98 \\
Care integration & $\mathbf{4 0}$ & $\mathbf{1 1 3}$ & $\mathbf{8 . 1 3} \pm \mathbf{0 . 8 0}$ & $\mathbf{7 . 8 5} \pm \mathbf{0 . 5 7}$ & $\mathbf{2 . 3 5}$ & $\mathbf{1 5 1}$ & $\mathbf{0 . 0 2}$ \\
Information System & 190 & 557 & $8.24 \pm 1.41$ & $8.14 \pm 1.40$ & 0.81 & 745 & 0.42 \\
Clinical comprehensiveness & 190 & 557 & $7.50 \pm 0.51$ & $7.47 \pm 0.50$ & 0.90 & 745 & 0.37 \\
Extended comprehensiveness & 190 & 557 & $7.08 \pm 1.23$ & $6.95 \pm 1.31$ & 1.19 & 745 & 0.23 \\
Family orientation & 190 & 557 & $7.36 \pm 1.17$ & $7.23 \pm 1.20$ & 1.31 & 745 & 0.19 \\
Cultural competence & 190 & 557 & $7.76 \pm 0.92$ & $7.70 \pm 0.95$ & 0.80 & 745 & 0.43 \\
Community orientation & $\mathbf{1 9 0}$ & $\mathbf{5 5 7}$ & $\mathbf{7 . 5 9} \pm \mathbf{1 . 4 2}$ & $\mathbf{7 . 3 0} \pm \mathbf{1 . 6 1}$ & $\mathbf{2 . 2 1}$ & $\mathbf{7 4 5}$ & $\mathbf{0 . 0 3}$ \\
Primary score & 190 & 557 & $7.17 \pm 0.55$ & $7.12 \pm 0.56$ & 0.95 & 745 & 0.34 \\
Overall score & $\mathbf{1 9 0}$ & $\mathbf{5 5 7}$ & $\mathbf{7 . 5 7} \pm 0.86$ & $\mathbf{7 . 4 1} \pm \mathbf{0 . 9 3}$ & $\mathbf{2 . 1 1}$ & $\mathbf{7 4 5}$ & $\mathbf{0 . 0 4}$ \\
\hline
\end{tabular}

Note: SD - standard deviation

${ }^{*} \mathrm{t}$ value - statistic resulting from the independent sample $t$ test

** Degree of freedom - statistic resulting from the independent sample t test.

Table 2. Summary of the comparisons of the models adjusted using logistic regression, for the service user/ dentist gender dyads and the nature of the Health Units. Curitiba, 2013.

\begin{tabular}{lccccc}
\multicolumn{1}{c}{ Variables } & Unit & MM & MF & FF & FM \\
\hline I think the dentist has a good understanding of what I say & PHC & No & Yes & No & Yes \\
or ask during the appointments. (D2) & PHC/FHS & NS & NS & NS & NS \\
The dentist allows enough time for me to talk about my & PHC & NS & NS & NS & NS \\
concerns or problems. (D5) & PHC/FHS & NS & NS & Yes & No \\
The dentist knows me more as a person than just as a & PHC & NS & NS & Yes & No \\
patient. (D7) & PHC/FHS & NS & NS & No & Yes \\
The dentist has detailed knowledge of all my health & PHC & Yes & No & NS & NS \\
problems, not just my oral health problems. (D11) & PHC/FHS & No & Yes & NS & NS \\
\hline
\end{tabular}

Note: $\mathrm{NS}^{*}$ - not significant.

it lacks statistical significance $(\mathrm{OR}=2.01 ; 95 \%$ CI 0.64-6.30). Women who prefer dentists of the male gender consider that they do not give them enough time to say what their problems are. In the same trend, it was possible to observe that in the answers to question D11, the male users who preferred dentists of the same gender (MM) stated that usually the dentist does not have detailed knowledge of their health problems, this fact being 2.24 (OR) greater than the MF dyad (95\%CI $0.70-7.11)$. This trend can mean that men who prefer dentists of the female gender consider that they pay more attention to patients' health problems. Again, caution is necessary in this interpretation given that the confidence interval includes the value of 1 and thus loses statistical significance.
In the case of the male users of the conventional PHC Units, a significant adjustment was also made $(\mathrm{p}=0.09)$, having an explanatory power of $93.5 \%$. In this adjustment, a trend shows that users who showed preference for a professional of the same gender (MM) stated that the dentists do not understand what they mention or ask during appointments when compared to the MF dyad (OR=6.50; 95\%CI 0.72-58.00). Once again, here the result should be viewed with caution owing to the confidence interval containing the value of 1 (Table 3 ).

About the evaluation of the female PHC Units user dyads, a significant adjustment $(\mathrm{p}=0.04)$ was performed, with explanatory power of $41.5 \%$. Women who prefer dentists of the same gender (FF) are more likely to answer "No" to the ques- 
Table 3. Results of the logistic regression performed on the service user dyads in relation to the preferences for the dentists' gender. Curitiba, 2013.

\begin{tabular}{llcccccc}
\hline $\begin{array}{c}\text { Health } \\
\text { Unit }\end{array}$ & $\begin{array}{c}\text { User gender/ } \\
\text { dentist gender dyads }\end{array}$ & Source & Value & Wald X & p & OR & $\begin{array}{c}\text { OR } \\
(\mathbf{C I}:-95 \%+95 \%)\end{array}$ \\
\hline PHC/FHS & MM/MF & Intercept & 0.57 & 0.00 & 0.99 & & \\
Unit & & D11-No & 0.80 & 1.88 & 0.17 & $\mathbf{2 . 2 4}$ & $0.70-7.11$ \\
& FF/FM & Intercept & 1.26 & 1509.80 & 0.00 & 0.99 & \\
& FM/FF & D5-No & 0.70 & 1.45 & 0.22 & 0.49 & $0.15-1.54$ \\
& & D7-No & -1.08 & 4.58 & 0.03 & $\mathbf{2 . 9 5}$ & $1.09-7.93$ \\
& & D5-No & 0.70 & 1.45 & 0.22 & 2.01 & $0.64-6.30$ \\
PHC Unit & MM/MF & Intercept & 0.73 & 0.00 & 0.99 & & \\
& & D2-No & 1.87 & 2.81 & 0.09 & 6.50 & $0.72-58.00$ \\
& & D11-No & -1.19 & 5.28 & 0.02 & $\mathbf{0 . 3 0}$ & $0.11-0.83$ \\
& \multirow{2}{*}{ FF/FM } & Intercept & 1.67 & 0.00 & 0.98 & & \\
& & D2-No & -1.02 & 4.04 & 0.04 & $\mathbf{2 . 7 9}$ & $1.02-7.57$ \\
& & D7-Yes & -0.03 & 0.00 & 0.92 & 1.03 & $0.50-2.13$ \\
\hline *Interpretation is always made using opposite dyads, e.g.MM/MF; FF/FM; FM/FF & & &
\end{tabular}

tion about the understanding of the questions they make during appointments in relation to the FM dyad (OR=2.79; 95\%CI 1.02-7.57). However, when answering question D7, the users of FF dyad tend to consider that the female dentists who care for them have detailed knowledge of all their health problems, and not just their oral health problems $(\mathrm{OR}=1.03$; 95\%CI 0.50-2.13), yet again with no significant confidence intervals and $\mathrm{p}$ values (Table 3 ).

\section{Discussion}

The first clear finding that the data allows to be made is the higher prevalence of female dentists in relation to male dentists who care for the interviewed users. The fact that there are three times more women than men dentists in the public health service, in this particular case, appears to confirm the disposition of women to seek formal employment and adhere to public services that provide care to the community in the future ${ }^{12,13}$. This preference is not free of contradictions, since the literature points out that there is a persistent set of financial problems, health problems and complaints about work, which reflect the dissatisfaction, sometimes unconscious of women in the practice of Dentistry ${ }^{25}$.

Service users of both genders showed a clear preference for being cared for by female dentists. This result is in keeping with another finding in the literature, in which the social belief was found that women have personal characteris- tics more favorable to practicing Dentistry ${ }^{26}$. The female gender is related to the expressions "attentive", "caring", "delicate", "patient", whereas men are associated with the expressions "secure", "careful", "strong"5,27. More important than the professional's sex characteristics are their ability to communicate and dialogue, as these favor a good relationship between the professional and the patient ${ }^{27}$.

However, as has been previously emphasized, there is great complexity in analyzing the social perception of professional practices, due to cultural and political-ideological constructions linked to the historical origins of these practices, which also leads to thinking about the specific issues of gender dissimilarity ${ }^{28}$. Gender refers to the set of social meanings attributed to sexual differences. The quantitative analyzes presented in this study show that the work is an enigmatic milieu perceived by different subjects, reproducing political and cultural constructions that frame gender relations and cross over the labor world, constituting one more component of its complexity ${ }^{24}$.

It would appear that in the case of the study in Curitiba, this is not a mere sampling artefact, biasing the analysis as a result of the majority of the sample being comprised of female dentists, since the users could be routinely cared for by women professionals and, nevertheless, preferring being cared for by male dentists.

With regard to the dentists' activities, the results show that the users who preferred to be cared for by women dentists do not confirm in their answers that the factors and attributes, 
which in the literature are related to care provided by the female gender, are associated with women dentists. In addition to technical skills, the personal interaction taking place between patient and dentist is highly valued. The patient's satisfaction and the quality of care are associated when the professional shows positive attitudes and communication skills and treats the patient as an individual ${ }^{29,30}$. It is true that when the answers to the questions relating to care in this study are analyzed separately, it can be seen that those users who prefer to be cared for by women dentists take into consideration active listening and care provided to the patient. This observation suggests a relationship with studies showing that female dentists value working with people and conversing with patients, choosing these qualities as being very important in their professional practice ${ }^{5,31}$.

In other factors and attributes studied, however, the difference does not show homogeneity capable of confirming statistical significance between the care provided by men or women, whether in conventional PHC Units or in PHC/ FHS Units. This finding may suggest convergence with the literature, in which service users do not perceive marked differences in the model of practice that defines the care provided by professionals of distinct genders ${ }^{27}$.

In the analysis of the attributes, represented on the PCTool-Users instrument, the result is a tad unfavorable to the female gender. Those who prefer to be cared for by male dentists emphasize "Care integration" and "Community guidance", slightly perceived more in the male professionals" work. This result may reflect a confined perception that men seem like having greater skill in clinical care coordination and that they guide the community in a more efficient manner. Caution is necessary in interpreting this result since the data regarding this perception is restricted to the sample studied. Although similar findings have been reported in the literature ${ }^{27}$, it refers to a private clinical study, in which prevails a marketing appeal. A possible hypothesis for this finding is the fact that the male figure is often associated with leadership, coordination, control. Although women outnumber men in public health care in Brazil, something that the sample of the present study also reveals, it is well known that women are still struggling to enter the top executive ranks. The situation has become more favorable in the local coordination of units, and begins to improve with more women assuming jobs of better remuneration/prestige, like Directories and Secretaries. However, from an international point of view the situation is still very unfavorable for women, warranting classic works that propose to offer guidance to overcome the most important barriers in health care leadership, regardless of gender ${ }^{32,33}$.

Despite the users stating in the aggregated answers that the services provided in PHC/FHS Units are superior when compared to conventional PHC Units, a finding already seen in the literature ${ }^{14}$, the preference they demonstrated for dentist gender had no influence in this comparison of Units model of care. The FHS, owing to the very conception of its model of care, enables active listening to and care of the patient to be extended to their family and their social environment, thereby converting care into effective health promotion. The literature contains various examples of the valuing of humanized care according to service users' testimonies ${ }^{27,34}$. Users stated that they value sensitivity and caring and relate them to the female gender, but this does not result in them expressing explicit preference for any type of Unit services ${ }^{27}$. This may imply there is a trend with users' preference for professional gender ${ }^{35}$, but gender characteristics did not show themselves to be relevant in the judgement of the services that users made.

The explanation of the non-association of preference for the gender of the professional and the judgement about the services may arise from professional training at university, regardless of the change in the profile of the students, the majority of whom in recent decades are female. Despite the recommendations of the Diretrizes Curriculares Nacionais - National Curricular Guidelines (MEC) ${ }^{36}$, which indicate more humanized and less technical training, the majority of the curricula and the majority of teachers have reproduced the biomedical and contents-based model, not providing space for valuing the personal characteristics of future professionals or emphasis on humanized care ${ }^{35-40}$. This is in spite of recommendations that in the future all nations should offer appropriate and acceptable quality care to the socio-cultural expectations of the population, when theoretical universal coverage can then translate into effective service coverage ${ }^{41}$.

In the literature, there are references to the fact that the term "feminization" should be understood not only as a process of quantitative change in the proportion of women in a particular area or sector of work, but as a qualitative change in the male or female qualities that tend to associate with the activities developed in the 
professions. There is even speculation in the literature that suggests that the feminization of the workforce is likely to have a negative impact on the availability of primary health care services, the shortage due to the fact that women would work less and provide less patient care compared to their male counterparts, although the actual scale of impact is difficult to determine with the currently available evidence, since few studies have looked at trends over time ${ }^{42}$.

Nonetheless, the power relations between the professions and a trend of sexual segmentation of the branches of education are favored by the school system itself. That is, the preconceived abilities of men and women are "constructions" built and reinforced from the beginning of the schooling process. Therefore, education plays a fundamental role in the naturalization of the roles of women and men ${ }^{43}$.

Based on the information obtained through the research instrument used in this study, the first conclusion is unambiguous. The users who prefer to be cared for by women dentists tend to have a better evaluation of primary health care in issues relating to active listening, whilst those who prefer to be cared for by male dentists highlight the attributes of Care Integration and Community Guidance. With regard to the other factors the evaluation is balanced, suggesting that gender characteristics have little influence on the users' perception of the work dentists play in the context analyzed.

This article aims to think the dynamics of this fertile web of knowledge and actions that constitute the professional practice of dentists in the public sector, from a specific angle, the incorporation of the gender perception of users of public dental services at the PHC and FHS. However, it has a limitation that users of the family health strategy already have a (pre) assigned professional responsible for each area of coverage, which determines not to be the user who chooses the professional. There was no intention to assess the scope or impact of gender mainstreaming in the field of oral health, but its novelty is marked by the perspective of addressing users of public health services on gender issues and their experience reflected in the perception of the quality of care they receive. This work is an invitation to collective reflection on ways to foster a gender approach in studies on work/occupational relations, pointing to areas of permeability at the frontier between disciplines. Therefore, it is important to point out the need for qualitative research to evaluate in depth the phenomena pointed out by this study.

\section{Collaborators}

MG Kfouri contributed to the study conception and design, and acquisition of data. ST Moysés contributed to the acquisition of data, analysis and interpretation of them. MCL Gabardo contributed to the analysis and interpretation of data and in drafting the manuscript. AC Nascimento contributed revising the text critically for important intellectual content and edited the manuscript. SV Rosa revised the entire manuscript. SJ Moysés participated in the study design, supervised the data analysis, the writing of the manuscript and contributed to the final approval of the version to be published. 


\section{References}

1. Ramakrishnan A, Sambuco D, Jagsi R. Women's Participation in the Medical Profession: Insights from Experiences in Japan, Scandinavia, Russia, and Eastern Europe. J Womens Health (Larchmt) 2014;23(11):927934.

2. Russo G, Gonçalves L, Craveiro I, Dussault G. Feminization of the medical workforce in low-income settings; findings from surveys in three African capital cities. Hum Resour Health 2015;13:64.

3. Probst ER. A Evolução da mulher no mercado de trabalho [artigo na Internet]. Blumenau (SC): Instituto Catarinense de Pós-Graduação (IPCG); 2011 [acessado 2011 Out 22]. Disponível em: http://www. mobilizadores.org.br/wp-content/uploads/2014/05/ artigo_jan_gen_a_evolucao_da_mulher_no_mercado_de_trabalho.pdf

4. McKay JC, Quiñonez CR. The feminization of Dentistry: implications for the profession. J Can Dent Assoc 2012;78:c1.

5. Kfouri MG, Moyses SJ, Moyses ST. Women's motivation to become dentists in Brazil. J Dent Educ 2013;77(6):810-816.

6. Brasil. Conselho Federal de Odontologia (CFO). Dados Estatísticos [página na Internet]. 2017 [acessado 2017 Set 29]. Disponível em: http://cfo.org.br/servicos-e-consultas/dados-estatisticos/

7. Hyson JM Jr. Women dentists: the origins. J Calif Dent Assoc 2002;30(6):444-453.

8. Ayers KM, Thomson WM, Rich AM, Newton JT. Gender differences in dentists' working practices and job satisfaction. J Dent 2008;36(5):343-350.

9. Naidoo S. Women in dentistry in South Africa: a survey of their experiences and opinions. SADJ 2005;60(7):284, 286, 288 passim.

10. Brasil. Ministério da Educação (MEC). Instituto Nacional de Estudos e Pesquisas Educacionais Anísio Teixeira (INEP). Sinopse Estatística da Educação Superior 2016. Brasília: Inep; 2017.

11. Chaves SCL, Almeida AMFL, Rossi TRA, Santana SF, Barros SG, Santos CML. Política de saúde bucal no Brasil 2003-2014: cenário, propostas, ações e resultados. Ciên Saude Colet 2017;22(6):1791-1803.

12. Morita SAS, Haddad AE, Araujo ME. Perfil atual e tendências do cirurgião dentista brasileiro. Maringá: Dental Press International; 2010. 98 p.

13. Davies L, Thomas DR, Sandham SJ, Treasure ET, Chestnutt IG. Factors influencing the career aspirations and preferred modes of working in recent dental graduates in Wales. Prim Dent Care 2008;15(4):157163.

14. Medina MG, Hartz ZM. The role of the Family Health Program in the organization of primary care in municipal health systems. Cad Saude Publica 2009;25(5):1153-1167.

15. Brito J. Trabalho e Saúde Coletiva: o ponto de vista da atividade e das relações de gênero. Ciên Saude Colet 2005;10(4):879-890.

16. Timofe MP, Albu S. Quality management in dental care: patients' perspectives on communication: a qualitative study. Clujul Med 2016;89(2):287-292.
17. Smith MK, Dundes L. The implications of gender stereotypes for the dentist-patient relationship. J Dent Educ 2008;72(5):562-570.

18. Asokan A, Kambalimath HV, Patil RU, Maran S, Bharath KP. A survey of the dentist atire and gender preferences on dentally anxious children. J Indian Soc Pedod Prev Dent 2016;34(1):30-35.

19. Pan American Health Organization (PAHO). Renewing Primary Health Care in the Americas: a position paper of the Pan American Health Organization/ World Health Organization (PAHO/WHO). Washington: PAHO; 2007.

20. Prefeitura Municipal de Curitiba. Secretaria Municipal de Saúde (SMS). Saúde Curitiba [Internet]. 2012 [acessado 2012 Jun 15]. Disponível em: http:// www.saude.curitiba.pr.gov.br/index.php/programas/ saude-bucal/rede-de-atencao

21. Starfield B, Shi L, Macinko J. Contribution of primary care to health systems and health. Milbank $Q$ 2005;83(3):457-502.

22. Harzheim E, StarfieldII B, RajmilIII L, Álvarez-Dardet C, Stein AT. Consistência interna e confiabilidade da versão em português do Instrumento de Avaliação da Atenção Primária (PCATool-Brasil) para serviços de saúde infantil. Cad Saude Publica 2006;22(8):16491659.

23. Mahler H. Primary health care comes full circle. Bull World Health Organ 2008; 86(10):747-748.

24. Villela W, Monteiro S, Vargas E. A incorporação de novos temas e saberes nos estudos em saúde coletiva: o caso do uso da categoria gênero. Ciên Saude Colet 2009;14(4):997-1006.

25. Moimaz SAS, Saliba NA, Blanco MRB. A força do trabalho feminino na Odontologia, em Araçatuba - SP. J Appl Oral Sci 2003;11(4):301-305.

26. Stewart FM, Drummond JR. Women and the world of dentistry. Br Dent J 2000;188(1):7-8.

27. Garbin AJI, Garbin CAS, Tiano AVP, Carvalho ML, Fagundes ACG. Marketing on dentistry: the perception of client about dental service of privative clinic. Rev Odontol UNESP 2008;37(2):197-202.

28. Schraiber LB. Necessidades de saúde, políticas públicas e gênero: a perspectiva das práticas profissionais. Ciên Saude Colet 2012;17(10):2635-2644.

29. Gurdal P, Cankaya H, Onem E, Dincer S, Yilmaz T. Factors of patient satisfaction/dissatisfaction in a dental faculty outpatient clinic in Turkey. Community Dent Oral Epidemiol 2000;28(6):461-469.

30. Yamalik N. Dentist-patient relationship and quality care 3. Communication. Int Dent J 2005;55(4):254256.

31. Scarbecz M, Ross JA. Gender differences in first-year dental students' motivation to attend dental school. $J$ Dent Educ 2002;66(8):952-961.

32. Robinson-Walker C. Women and leadership in health care: The journey to authenticity and power. San Francisco: Jossey-Bass; 1999.

33. World Health Organization (WHO). Gender, women and primary health care renewal: a discussion paper. Geneva: WHO; 2010. 
34. Nascimento AC, Moysés ST, Bisinelli JC, Moysés SJ. Oral health in the Family Health Strategy: a change of practices or semantics diversionismo. Rev Saude Publica 2009;43(3):455-462.

35. Zoboli ELCP. A redescoberta da ética do cuidado: foco e ênfase nas relações. Rev esc enferm USP 2004;38(1):21-27.

36. Brasil. Ministério da Educação (MEC). Diretrizes Curriculares Nacionais do Curso de Graduação em Odontologia. Brasília: Conselho Nacional de Educação. Câmara de Educação Superior; 2002.

37. Moysés ST, Moysés SJ, Kriger L, Schimitt EJ. Humanizando a educação em Odontologia. Rev ABENO 2003;3(1):58-64.

38. Saliba NA, Moimaz SA, Garbin CA, Diniz DG. Dentistry in Brazil: its history and current trends. J Dent Educ 2009;73(2):225-231.

39. Baltazar MMDM, Moysés SJ, Bastos CCBC. Profissão, docente de odontologia: o desafio da pós-graduação na formação de professores. Trab Educ Saude 2010;8(2):285-303.

40. Lazzarin HC, Nakama L, Cordoni Júnior L. Percepção de professores de odontologia no processo de ensinoaprendizagem. Ciên Saude Colet 2010;15(1):18011810.

41. World Health Organization (WHO). Global strategy on human resources for health: workforce 2030 ender, women and primary health care renewal: a discussion paper. Geneva: WHO; 2016.

42. Hedden L, Barer ML, Cardiff K, McGrail KM, Law MR, Bourgeault IL. The implications of the feminization of the primary care physician workforce on service supply: a systematic review. Hum Resour Health 2014;12:32.

43. Costa SM, Durães SJA, Abreu MHNG. Feminização do curso de odontologia da Universidade Estadual de Montes Claros. Ciên Saude Colet 2010;15(Suppl. 1):1865-1873. 
